\title{
Efficacy of Different LOAD-Intensity and Time-Under- Tension Exercise Interventions for Achilles Tendinopathy (The LOADIT Trial): A Randomised Pilot Trial
}

Fatmah Hasani ( $\square$ fatmah.hasani@monash.edu )

Monash University Faculty of Medicine Nursing and Health Sciences https://orcid.org/0000-00016497-6107

\section{Terry Haines}

Monash University Faculty of Medicine Nursing and Health Sciences

Shannon E Munteanu

La Trobe University College of Science Health and Engineering

\section{Peter Schoch}

McKenzie Institute Australia

Bill Vicenzino

The University of Queensland School of Health and Rehabilitation Sciences

\section{Peter Malliaras}

Monash University Faculty of Medicine Nursing and Health Sciences

Research article

Keywords: Achilles tendinopathy, Rehabilitation, Exercise Parameters

Posted Date: December 1st, 2020

DOI: https://doi.org/10.21203/rs.3.rs-113432/v1

License: (c) (i) This work is licensed under a Creative Commons Attribution 4.0 International License. Read Full License 


\section{Abstract}

Background: One potential reason for disparate outcomes of exercise for Achilles tendinopathy is poor knowledge about whether exercise parameters (i.e. different exercise doses) influence outcome. Whether parameters that are important for tendon adaptation influence clinical outcomes in Achilles tendinopathy has not been investigated. Therefore, this research aimed to assess the feasibility of conducting a definitive randomised trial to investigate the efficacy of different load-intensity and time-under-tension exercise parameters for Achilles tendinopathy.

Methods: A factorial four-arm, randomised trial. Forty-eight male participants (18-70 years old) with midportion Achilles tendinopathy ( $\geq 3$ months) were recruited. Participants were randomly allocated to high ( 6 repetition maximum) or low intensity (18 repetition maximum) exercise, performed with either high (6 seconds per cycle) or low (2 seconds per cycle) time-under-tension. Participants performed 12-weeks of standing and seated calf raise exercises three times per week in a gym setting using a Smith machine. One session per week was supervised (via teleconference). Primary feasibility outcomes (recruitment and retention rate, exercise adherence and fidelity [i.e. time-under-tension, volume, load intensity], incidence of adverse events, health care use and productivity cost) were collected weekly. Means and standard deviations were determined for parametric data, medians and interquartile range for non-parametric continuous data, and frequency counts for discrete data.

Results: Total recruitment (76\%) and retention (90\%) rates were high. Exercise adherence ranged from 45 to $63 \%$ and fidelity ranged from 8 to $83 \%$ across the groups. Thirty-one participants reported 64 adverse events over the 3 months. Twenty-one participants (70\%) reported mild events. Participants reported reduced presenteeism more than absenteeism.

Conclusions: A definitive randomised trial is feasible. The proposed trial design and interventions demonstrated acceptable recruitment and retention rates and safety profile. However, exercise fidelity and adherence to the gym-based intervention was not acceptable. Strategies to improve intervention adherence and fidelity should be considered in future trials.

Trial registration: Australian New Zealand Clinical Trials Registry, ACTRN12618001315202. Registered retrospectively on August 6th, 2018.

\section{Background}

Mid-portion Achilles tendinopathy is a common musculoskeletal condition characterised by localised Achilles tendon load-related pain and dysfunction [1]. The pain mechanisms in tendinopathy are not clear but are thought to involve local nociception mediated by changes within the tenocytes [2]. The etiology of tendinopathy is complex and multifactorial [3], but imbalance between the load demands placed on the tendon and its capacity to remodel is considered a major factor [4]. Both athletes and sedentary people can be affected, and many suffer profound and longstanding impairment of activities such as walking and running $[5,6]$. 
Exercise-based treatments that restore the load capacity of the tendon have become the focus of management for Achilles tendinopathy and are recommended in systematic reviews and clinical practice guidelines [7-9]. Despite being a first-line recommended treatment, the benefit from exercise is variable [10]. A recent longitudinal study found $60 \%$ had continued pain and disability after 5 years despite exercise interventions, and $48 \%$ sought additional treatment including injections and surgery [11]. One potential reason for disparate outcomes of exercise for Achilles tendinopathy is poor knowledge about whether exercise parameters (i.e. different exercise doses) influence outcome. Exploration of exercise dose-response in Achilles tendinopathy is warranted. Knowing whether certain exercise parameters improve outcomes for Achilles tendinopathy management will assist in developing more effective exercise approaches [12].

Many parameters can be influenced in exercise prescription, including load-intensity (e.g. repetition maximum [RM], maximal voluntary contraction), volume (repetitions and sets), and time under tension per contraction [13]. A systematic review investigating exercise response (i.e. adaptative outcomes such as tendon stiffness) in healthy Achilles and patellar tendons concluded that load-intensity is a key determinant of tendon tissue adaptation to load, and the type of contraction (e.g. eccentric versus concentric) did not influence adaptation [14]. Load-intensity results in greater tendon tissue strain which deforms tendon cells and triggers anabolic cell signalling [15]. There is also evidence that longer duration contractions at the same intensity result in greater Achilles tendon adaptation [16], most likely because there is time-dependent transmission of external load to the tendon cytoskeleton and cells. Whether parameters that are important for tendon adaptation such as load-intensity and duration of contraction (or time-under-tension) influence clinical outcomes in Achilles tendinopathy has not been investigated.

\section{Aims}

The primary aim of this study was to determine the feasibility of conducting a definitive randomised trial to determine the efficacy of different load-intensity and time-under-tension exercise parameters for Achilles tendinopathy. The key outcomes were (i) rate of participant recruitment, conversion, and retention, (ii) ability to perform the interventions per-protocol (adequate exercise fidelity and adherence based on weekly videoconference assessment), (iii) incidence and type of adverse events, (iv) use of rescue medication and co-interventions, and ( $v$ ) feasibility of future economic evaluation. The secondary aim was to provide estimates of the variability of key outcomes (pain and disability, participant perception of change, satisfaction, health-related quality of life, physical activity, psychological measures, plantarflexor function) to enable estimation of the sample size for a future definitive trial.

\section{Methods}

\section{Design}

LOADIT (LOAD- Intensity and Time-under-tension) is a four-arm, factorial randomised pilot trial. The two factors, each with two levels, are load-intensity (determined by RM, the maximum mass that can be lifted for a given number of repetitions) and time-under-tension (determined by seconds). Participants were 
randomly allocated into one of four groups: 6 RM with two second repetitions; 6 RM with 6 second repetitions; $18 \mathrm{RM}$ with two second repetitions; or $18 \mathrm{RM}$ with 6 second repetitions group (Figure 1). The methods are described in the published protocol [17]. The study was reported in accordance with the CONSORT extension for randomised pilot and feasibility trials [18] and the TIDieR guide [19]. The protocol was registered (August 2018; ACTRN 12618001315202. The trial was approved by the Human Research Ethics Committee at Monash University (ethics number 2018-1366-20711).

Figure 1. Trial profile. Abbreviation: HL, High load; HT, High time-under-tension; LL, Low load; LT, Low timeunder-tension; VISA-A, Victorian Institute of Sports Assessment - Achilles; EQ-5D-5L, Health-related Quality of Life; WPAI, Work Productivity and Activity Impairment; PIC, Patient Impression of Change; PCS, Pain Catastrophising Scale; PAR, Physical Activity Recall questionnaire; PASS, Patient-Acceptable Symptom State instrument for satisfaction; MVIC, Maximal Voluntary Isometric Contraction; FM10\%, Force match at $10 \%$; RTD, Rate of Torque Development; RM, repetition maximum.

\section{Study population}

Participants were included if they were male, aged between 18 to 70 years with a history of mid-portion Achilles tendon pain in either or both legs for $\geq 12$ weeks, and scored $\leq 75$ on the Victorian Institute of Sports Assessment - Achilles questionnaire (VISA-A). Men were the focus because of evidence that tendon adaptation to exercise (and therefore possibly clinical outcomes) may be confounded by sex [20]. The clinical diagnosis was based on the clinical presentation, physical examination and ultrasound imaging done by practicing physiotherapist (FH). Exclusion included a history of Achilles tendon rupture, surgery in the symptomatic lower limb(s) or any health conditions that may interfere with the execution of the exercise interventions. Participants were also excluded if they had had an injection or received strength exercise treatment for their Achilles tendon pain within the last 3 months.

\section{Recruitment and setting}

Participants were recruited via social media (i.e. Facebook, Twitter), and by posting study information on relevant internet websites (e.g. sports clubs and forums), as well as referral from health professionals in Melbourne. All screening assessments and data collection were conducted at a single centre (Monash University, Melbourne, Victoria, Australia) between July 2018 and May 2019. Responders to the advertisements were asked to provide their contact number. They were contacted and screened via the telephone by research assistants who also provided trial information. Those who confirmed interest in the study (either at the time of the telephone call or by re-initiating contact with the researcher after the initial call) were invited to attend a screening visit to confirm their eligibility. All participants provided oral and written informed consent before joining the trial.

\section{Randomisation and blinding}

A randomisation sequence with permuted blocks of variable size was created using an online randomisation service (Sealed Envelope Ltd, London) and then concealed in opaque sealed envelopes by 
a researcher who was not in contact with participants $(\mathrm{TH})$. The treating physiotherapists and participants were not blinded. Each participant received a scripted explanation of the trial which included that there is uncertainty about whether any of the exercise interventions would be superior. The participants were assigned to intervention by the same investigator (PM). The investigator (FH) who administered and collected the secondary outcomes and the statistician were blinded to group allocation.

\section{Exercise interventions}

Participants performed four sets of unilateral standing and seated isotonic calf raise exercise to load the ankle plantarflexor complex (both sides, one leg at a time), three times per week for 12 weeks, with standardised rest times (90 seconds between sets). The 12-week endpoint was chosen because it has been shown to be a sufficient timeframe for exercise to have a clinically meaningful effect on Achilles tendinopathy pain and function [21]. Both isotonic exercises were performed in a Smith machine at a local gymnasium (gym membership was provided free of charge to participants, if required). A practicing physiotherapist monitored one session per week (via teleconferencing software [Zoom $\AA$ ]) and provided exercise progression and technique feedback. During this session, exercise adherence and fidelity (prior to providing feedback), adverse events, use of co-interventions, and productivity data were collected. Participants were taught calf raise exercise technique [17] using parameters specific to their group allocation (Table 1) and the exercises were externally paced using a metronome (via smartphone application). Participants were instructed to exercise to volitional failure and how to progress and regress exercise based on difficulty with the exercise and pain experienced. After the baseline testing of the repetition maximum, exercise intensity was adjusted down by $10 \%$ in all groups to reduce the risk of muscle soreness related to commencement of unaccustomed exercise. Further exercise details are provided in additional file 1 and the protocol [17].

\section{Table 1. Calf exercise dosage for each group.}

Participants were provided with education related to tendon pain mechanisms and acceptable levels of pain during exercise and activity. Participants were advised to consume up to four $\mathrm{g} /$ day pain-relieving medication [22] (i.e. paracetamol), if required. Participants received advice to gradually increase walking, running and sports activity if Achilles tendon pain during these activities was not beyond level 5 out of 10 on an 11-point numerical pain rating scale (NPRS) $0=$ no pain, $10=$ worst pain imaginable) [23]. They were also advised it was acceptable for pain after sport activities to temporarily increase as long as it returned to baseline levels on a tendon loading test such as single-leg submaximal hop or single leg calf raise, within approximately 24 hours.

\section{Outcome measures}

\section{Primary outcomes}

\section{Rate of conversion, recruitment, and retention}


The conversion rate was the proportion of people who consented divided by those who met the criteria. The recruitment rate was the number of participants recruited per month. Retention was the proportion of recruited participants who completed the 12-week outcome assessment. The conversion and retention success criteria were $\geq 20 \%$ and $80 \%$ respectively.

\section{Exercise adherence and fidelity}

\section{Incidence of adverse events}

An adverse event was defined as any unintended symptom associated with the study which may or may not be related to the intervention [24]. The frequency (number of participants and number of cases), nature (e.g. sprained ankle, a muscle tear or tendon pain worsening), and severity (mild [< 48 hours], moderate [up to 7 days], or severe [ $>7$ days or requiring medical attention]) were recorded at the weekly videoconference session. Individuals experiencing adverse events were managed by the research team or triaged to an appropriate medical facility.

\section{Use of co-interventions}

The frequency of the use of paracetamol medication and other co-interventions was recorded.

\section{Feasibility of future economic evaluation}

These costs were divided into the following:

- The direct intervention costs: This included the gym membership (estimated 15 AUD per week), physiotherapy treatment and participant screening time (estimated rate 150 AUD per hour). Other direct cost for co-interventions were calculated based on number of days the co-intervention $x$ market price or by estimating the once off cost of the health product.

- The indirect cost or productivity cost included the absenteeism (time loss from work due to Achilles tendinopathy) and presenteeism (productivity loss while at work due to Achilles tendinopathy) were assessed using the Health-related work productivity questionnaire (WPAI) [25]. Absenteeism cost was calculated by multiplying this percentage score $\times$ the average wage rate in Australia (estimated at 45 AUD per hour) according to Australian Bureau of Statistics figures [26]. The costs of productivity loss due to presenteeism were calculated by multiplying the percentage of rating scale indicating the degree of health problem affected productivity while working scorex number of hours actually worked per week) $\times 45$ AUD.

\section{Secondary outcomes}

\section{Patient-reported outcomes}

Nine patient-reported outcomes were included: (i) The severity of pain and disability were assessed using the VISA-A [27] and a modified version intended for non-athletes [28]; (ii) The worst pain level experienced 
in the last week with an NPRS (11- point scale, 0 = no pain, 10 = worst imaginable pain); (iii) Patient Impression of Change (PIC) which is a 7-point Likert scale including two questions; 1) "How would you describe your Achilles tendon pain now, compared to before you began the treatment?" and 2) "How would you describe your ability to perform physical activities (such as walking, running, housework) now, compared to before you began the treatment?" [29]; (iv) Patient-Acceptable Symptom State instrument [30] which involved a yes or no response to two questions: "Currently are you satisfied with your condition?", and "Would you recommend this treatment to another person who has Achilles pain?"; (v) Health-related quality of life was measured using the 5-level EQ-5D version (EQ 5D 5L index value and overall health state [VAS]); (vi) Physical activity using 7-day Recall Physical Activity Questionnaire [31]; (vii) Fear of movement or re-injury: Kinesiophobia was measured with the Tampa Scale for Kinesiophobia (TSK) [32]; (viii) Pain catastrophising was measured using the Pain Catastrophising Scale (PCS) [33], in addition to

the painDETECT questionnaire (at baseline testing only) which was implemented to screen for neuropathic pain [34].

\section{Plantarflexor strength tests}

A custom-built ankle dynamometer (participants seated with $50^{\circ}$ knee flexion) was used to assess plantarflexor torque during maximal voluntary isometric contraction (MVIC), rate of torque development (RTD) and force matching (see additional file 2 for details). Force matching involved maintaining ankle plantarflexor force equivalent to $10 \%$ of their MVIC with visual feedback on a screen 1.5 meters in front of them.

\section{Sample size}

We made a pragmatic decision that we would be able to achieve our feasibility aim by recruiting 48 participants to be randomised into one of four factorial arms ( $n=12$ per trial arm as a rule of thumb recommended by Julious) [35].

\section{Data management and analysis}

Entered data were checked for accuracy by two study investigators (FH, PM). Statistical analysis was undertaken on coded data (group allocation concealed). Data from the most painful side were analysed for people with bilateral Achilles pain. SPSS (version 25, IBM Corp., Armonk, NY, USA) was used for statistical analysis. Means and standard deviations were determined for parametric data, medians and interquartile range for non-parametric continuous data, and frequency counts for discrete data. Mean difference (MD) and standard mean difference (SMD = MD/pooled standard deviation) from baseline to 6 and 12 weeks and 95\% confidence intervals were calculated (RevMan, version 5.4, The Nordic Cochrane Centre, Copenhagen, DK) for all secondary outcomes. The SMD's were interpreted as very large when $\geq$ 1.2, moderate when $\geq 0.6$, and small when $\geq 0.2$ [36]. The PIC 7-point Likert scale was dichotomised for analyses ("very much improved" and "improved" represents treatment effectiveness). The MVIC torque 
data $(\mathrm{Nm})$ were extracted directly from PowerLab (AD Instruments Corp, Dunedin, NZ) whereas RTD data $(\mathrm{Nm} / \mathrm{s})$ and force match data were exported to Excel (Microsoft Corporation, Redmond, WA). The peak RTD (0-50 Nm scale window) was analysed using a custom-written software program (rehabtools.org, Sunshine Coast, Australia). The coefficient of variation of torque for the 15 second sampling window was used to represent fluctuations in force-matching (ratio of standard deviation to the mean torque). Patterns of missing data were analysed using Little's Missing Completely at Random test [37]. Data substitution was not applied for missing data given this was a feasibility study with a small sample. However, an effort was made to collect the patient-reported outcomes data especially for those who discontinued the intervention.

\section{Results}

The sample consisted of 48 men, aged 20 to 65 years (mean age $43.2 \pm 10.4$ years). The duration of symptoms ranged from 3 to 240 months (two outliers of 240 months, median $=24$ ). The BMI ranged from 20 to $45 \mathrm{~kg} / \mathrm{m}^{2}$. None of the participants reported neuropathic pain (Table 2). From 1,043 initial contacts, 86 people were screened in-person, 63 were eligible and 48 consented (Figure 2).

Table 2. Participant characteristics at baseline. Values are mean (SD) unless otherwise noted.

Figure 2. The CONSORT flow diagram of participants through the study.

\section{Primary outcomes}

\section{Rate of conversion, recruitment, and retention}

Both conversion and retention rate were acceptable. The conversion rate was $76 \%$ (48/63) (Figure 2). The recruitment rate ranged from 3 to 20 per month over the 6-months recruitment window (Figure 3 ) because the Facebook strategy was intermittent (i.e. stopped for 4 months during holiday periods). Forty-one (85\%) participants were recruited via Facebook (total spend \$9,052.91 AUD; average spend of \$221 AUD per person recruited) and the remaining (7 [15\%]) via clinical networks and the community.

Five participants did not complete the study (Figure 2) giving a retention rate of 90\% (43/48). Four participants dropped out because of the burden of the intervention, and one participant dropped out due to severe back pain. Between 86 and $98 \%$ of outcome data were collected at each timepoint.

Figure 3. Monthly and cumulative recruitment to the feasibility trial.

\section{Exercise adherence and fidelity}

Exercise adherence and fidelity data are presented in Table 3. The proportion of adherence to the supervised sessions was 71 to $92 \%$ and total adherence was 49 to $68 \%$ (1-2 sessions completed out of 3 per week). Fidelity varied substantially between criteria, with highest fidelity (58 to $83 \%$ ) seen for the 
volume criterion. The time-under-tension criterion averaged $<66 \%$ across all groups. Fidelity was lower for high-intensity groups (Figure 4). In general, the success rate (66\%) was not reached for both adherence and fidelity outcome.

Figure 4. Exercise fidelity of the individual exercise dose parameters for each participant per group.

\section{Incidence of adverse events}

There were between six and eight participants per group who experienced an adverse event and a total of 64 reported adverse events over the 3 months (Table 3 ). Twenty-one participants (70\%) reported mild adverse events that included Achilles pain, headache, and pain in other areas [shoulder, wrist, back]). Eight participants (17\%) reported moderate adverse events (included back, anterior knee and shin pain) that occurred more frequently in the high-intensity groups ( $21 \%$ versus $13 \%)$. There was only one serious adverse event that was not related to the interventions (back pain that required surgery).

\section{Use of co-interventions}

There were similar rates of co-intervention use between groups (Table 3). Common co-interventions included myotherapy, acupuncture, and topical non-steroidal anti-inflammatory agents (i.e. diclofenac gel). Four to six participants in each group reported using paracetamol for their associated pain, during the 12 weeks of intervention.

Table 3. Feasibility outcomes. Values are n (\%) unless otherwise noted.

\section{Feasibility of future economic evaluation}

Over the three-month study period, the direct cost was 1,050 AUD and indirect cost was 37 AUD per participant. This included costs associated with participants who withdrew or missed sessions. The three months gym membership cost was 180 AUD per participant. Average presenteeism was valued at 412 AUD per participant over the three-month study period. Only one participant reported absenteeism (8 hours) due to their Achilles tendinopathy, which equated to a cost of 765 AUD.

\section{Secondary outcomes}

\section{Patient-reported outcomes}

All groups displayed improvement in self-reported outcome measures during the study (Table 4). At 12 weeks, the mean improvement in VISA-A scores was between 26 to 40 points. The worst pain over the last 
week decreased by an average of 3 to 4 points. More than 75\% of participants reported an improvement in pain and function and satisfaction with condition post-intervention.

Table 4. Patient-reported outcomes with effect estimates. Values are mean (SD) unless otherwise noted.

\section{Plantarflexor strength tests}

All groups displayed improvement in all strength tests (Table 5). The magnitude of mass lifted increased by about $25 \%$ in seated and $10 \%$ in the standing positions (Figure 5 ).

\section{Table 5. Performance outcomes with effect size estimates and mean difference (mean \pm SD)}

Figure 5. Overall absolute mass lifted during the intervention.

\section{Discussion}

This pilot randomised trial has demonstrated that the interventions are safe (only one unrelated serious adverse event), and the rate of conversion, recruitment, and retention were acceptable. Adherence to the gym-based intervention was acceptable for the weekly videoconference supervised sessions but not for the two non-supervised sessions. Exercise fidelity varied substantially between criteria and was unsatisfactory for the time-under-tension criterion across all groups. Prior to progressing to a full-scale trial, further work is necessary to identify and trial strategies to improve exercise adherence and fidelity. The major cost appeared to be related to provision of the intervention. Unlike other chronic pain conditions [38], the amount of time lost from work and productivity loss at work related to this condition was minimal, which raises the question whether economic evaluation is warranted in a full-scale trial.

Our interventions have similar characteristics to the 'heavy slow resistance training' intervention utilised by Beyer et al. [39]. Heavy slow resistance involves three sessions of gym-based calf loading exercise per week. There were, however, differences in reported exercise adherence between our pilot trial (49 to $68 \%$ ) and the Beyer et al. trial ( $92 \%$ for heavy slow resistance). Discrepant adherence rates may be explained by methodological differences between the trials. First, Beyer et al. prescribed three 2-legged exercises (three exercises in total) which would have been less time consuming than the four exercise ( 2 on each limb) in our study. Second, the socio-geographical environment (Copenhagen versus Melbourne) may have influenced adherence (e.g. commute time to the gym or traffic congestion favouring Copenhagen). Third, the adherence data was recorded more frequently in our study (weekly by our physiotherapists from patient report during the teleconference sessions versus a single supervised session plus patient diaries in the Beyer study) which may have influenced accuracy by reduced recall bias [39]. Future studies could benefit from better understanding barriers to patients' exercise adherence, in order to identify and implement strategies to improve adherence across all trial groups, such as more supervised exercise sessions, either synchronously or asynchronously (e.g. via patients self-recording exercise sessions). 
Exercise fidelity was important for ensuring that the exercise groups varied in the exercise parameters that were being compared including volume, intensity and time-under-tension. There was varied fidelity rate across all the trial groups with the lowest fidelity seen for the time-under-tension criterion ( 25 to $42 \%$ ). Adequate time-under-tension was achieved if calf raise tempo was judged by the telerehabilitation rater (physiotherapist) to be in time with metronome (auditory cue) during the videoconference sessions. Errors related to poor internet connection and delayed or freezing video that may impact the rating, were reduced by re-rating any trials in which this was perceived by the rater. This criterion may have been too stringent because the overall time-under-tension may have been satisfactory even if there were timing violations for some of the repetitions. In future trials comparing different levels of time-under-tension, we recommend comparing total time-under-tension per set. Although they did not assess time-under-tension, Sancho et al. recently reported exercise (calf raises and hopping) fidelity ranging from 22 to $64 \%$ for volume and load-intensity [40].

High-intensity groups had lower fidelity compared to low-intensity groups. Fidelity strategies may need to be targeted towards the high-intensity groups as they seem to have more difficulty performing the required load-intensity. This could be a practical issue i.e. participants lifting heavy weight, or fear issues.

At 12 weeks, there was an improvement in patient-reported pain and function scores measured with the VISA-A questionnaire, ranging from 26 to 40 points. In a recent systematic review of 31 studies among individuals with Achilles tendinopathy undergoing a calf muscle loading program mean (SD) change in patient-reported pain and function (measured using the VISA-A questionnaire) was 21.1 (6.6) points [10]. Our findings are one to three standard deviations above this pooled mean. A clinically meaningful change is suggested to be 10 -points $[28,39,41]$ and this is also the Cochrane collaboration recommended minimal clinically important difference for a 100-point function scale [42]. However, our study did not include a control group, so the influence of natural history or placebo is not known. Other secondary outcomes also changed favourably in all groups. The improvements were likely to be clinically meaningful as the estimated effect size were moderate to large $\geq 0.6$.

Variability of the VISA-A outcome in our data can be used to estimate the sample size for a future fullscale randomised controlled trial. One hundred and fourteen participants (i.e. 57 per group) would provide power of over $80 \%$ to detect an effect size of 10 -points on the VISA-A questionnaire $[28,39,41]$ with the significance level set at $p<0.05$. A pooled standard deviation of 17.2 was derived from the 4 arms in this pilot study. This calculation accounts for a $10 \%$ drop-out rate.

\section{Conclusions}

The results of this study suggest that high and low-intensity and time-under-tension loading protocols are feasible and safe for individuals with mid-portion Achilles tendinopathy. Future trials should consider strategies to optimise exercise adherence and fidelity.

\section{Abbreviations}


RM: repetition maximum; VISA-A: Victorian Institute of Sports Assessment - Achilles questionnaire; MVIC: Maximal Voluntary Isometric Contraction; RTD: Rate of Torque Development; NPRS: Numerical Pain Rating Scale; PIC: Patient Impression of Change; WPAI: Work Productivity and Activity Impairment Questionnaire.

\section{Declarations}

\section{Ethics approval and consent to participate}

All experimental procedures have been approved by the Human Research Ethics Committee at Monash University (ethics number 2018-1366-20711) for study protocol version 3 dated 10/07/2018 and all supporting documents. Any significant modification to the study protocol will require a formal amendment. written informed consent was obtained from all participants.

\section{Consent for publication}

Not applicable.

\section{Availability of data and materials}

The datasets used and/or analysed during the current study are available from the corresponding author on reasonable request.

\section{Competing interests}

PM is a member of the editorial board (Associate Editor) of this journal. Peter Schoch is a Faculty member of the McKenzie Institute Australia and McKenzie Institute International and receives payment for teaching post graduate courses in the McKenzie Method of Mechanical Diagnosis and Therapy. $\mathrm{He}$ has no direct affiliation with the International Mechanical Diagnosis and Therapy Research Foundation. $\mathrm{FH}, \mathrm{TH}, \mathrm{SEM}$ and BV declare that they have no competing interests.

\section{Funding}

This research was funded by a grant from the International Mechanical Diagnosis and Therapy Research Foundation (IMDTRF). Funding source did not play a role in any aspects relating to the study design, data collection, data analysis and management, interpretation of data, writing of the report, or publication and dissemination of study findings. 


\section{Authors' contributions}

All authors (FH, TH, SEM, BV, PS and PM) contributed to the conception, design of the trial and interpretation the data. FH and PM conducted the data collection. FH and TH completed the data analysis. PM contributed to training and supervision of the physiotherapists involved on the trial. $\mathrm{FH}$ drafted the manuscript and all co-authors provided critical revisions to the clinical and intellectual content. All authors have read and approved the manuscript.

\section{Acknowledgments}

We would like to acknowledge all participants, physiotherapists, and research assistants participated in this trial.

\section{Clinical messages}

- Conducting a definitive randomised trial to determine the efficacy of different load-intensity and timeunder-tension exercise parameters for Achilles tendinopathy is feasible.

- Strategies designed to improve exercise adherence and fidelity are necessary prior to progressing to a full-scale trial.

- The findings provide important preliminary information regarding treatment effect sizes of the interventions described.

\section{References}

1. Habets $B$, van Cingel RE: Eccentric exercise training in chronic mid-portion Achilles tendinopathy: a systematic review on different protocols. Scand J Med Sci Sports 2015, 25(1):3-15.

2. Rio E, Moseley L, Purdam C, Samiric T, Kidgell D, Pearce AJ, Jaberzadeh S, Cook J: The pain of tendinopathy: physiological or pathophysiological? Sports Med 2014, 44(1):9-23.

3. Abate M, Silbernagel KG, Siljeholm C, Di lorio A, De Amicis D, Salini V, Werner S, Paganelli R: Pathogenesis of tendinopathies: inflammation or degeneration? Arthritis Res Ther 2009, 11(3):235235.

4. Cook JL, Purdam CR: Is tendon pathology a continuum? a pathology model to explain the clinical presentation of load-induced tendinopathy. Br J Sports Med 2009, 43(6):409-416.

5. de Jonge S, van den Berg C, de Vos RJ, van der Heide HJ, Weir A, Verhaar JA, Bierma-Zeinstra SM, Tol $\mathrm{JL}$ : Incidence of midportion Achilles tendinopathy in the general population. Br J Sports Med 2011, 45(13):1026-1028.

6. Turner J, Malliaras P, Goulis J, McAuliffe S: "It's disappointing and it's pretty frustrating, because it feels like it's something that will never go away." A qualitative study exploring individuals' beliefs and 
experiences of Achilles tendinopathy. PloS one 2020, 15(5):e0233459-e0233459.

7. Martin RL, Chimenti RL, Cuddeford T, Houck J, Matheson JW, McDonough CM, Paulseth S, Wukich DK, Carcia CR: Achilles pain, stiffness, and duscle power deficits: didportion Achilles tendinopathy revision 2018. JOSPT 2018, 48(5):A1-a38.

8. Malliaras P, Barton CJ, Reeves ND, Langberg H: Achilles and patellar tendinopathy loading programmes : a systematic review comparing clinical outcomes and identifying potential mechanisms for effectiveness. Sports Med 2013, 43(4):267-286.

9. Kingma JJ, de Knikker R, Wittink HM, Takken T: Eccentric overload training in patients with chronic Achilles tendinopathy: a systematic review. Br J Sports Med 2007, 41(6):e3-e3.

10. Murphy M, Travers M, Gibson W, Chivers P, Debenham J, Docking S, Rio E: Rate of improvement of pain and function in mid-portion Achilles tendinopathy with loading protocols: a systematic review and longitudinal meta-analysis. Sports Med 2018.

11. van der Plas A, de Jonge S, de Vos RJ, van der Heide HJ, Verhaar JA, Weir A, Tol JL: A 5-year followup study of Alfredson's heel-drop exercise programme in chronic midportion Achilles tendinopathy. $\mathrm{Br}$ J Sports Med 2012, 46(3):214-218.

12. Malliaras $\mathrm{P}$ : Understanding mechanisms to improve exercise interventions in tendinopathy. Phys Ther Sport 2016.

13. Bird SP, Tarpenning KM, Marino FE: Designing resistance training programmes to enhance muscular fitness. Sports Med 2005, 35(10):841-851.

14. Bohm S, Mersmann F, Arampatzis A: Human tendon adaptation in response to mechanical loading: a systematic review and meta-analysis of exercise intervention studies on healthy adults. Sports Med Open 2015, 1(1):7.

15. Kjaer M: Role of extracellular matrix in adaptation of tendon and skeletal muscle to mechanical loading. Physiol Rev 2004, 84(2):649-698.

16. Bohm S, Mersmann F, Tettke M, Kraft M, Arampatzis A: Human Achilles tendon plasticity in response to cyclic strain: effect of rate and duration. J Exp Bio/ 2014, 217(Pt 22):4010-4017.

17. Hasani F, Haines T, Munteanu SE, Vicenzino B, Malliaras P: Efficacy of different load intensity and time-under-tension calf loading protocols for Achilles tendinopathy (the LOADIT trial): protocol for a randomised pilot study. Pilot Feasibility Stud 2020, 6(1):99.

18. Eldridge SM, Chan CL, Campbell MJ, Bond CM, Hopewell S, Thabane L, Lancaster GA: CONSORT 2010 statement: extension to randomised pilot and feasibility trials. Pilot Feasibility Stud 2016, 2:64.

19. Hoffmann TC, Glasziou PP, Boutron I, Milne R, Perera R, Moher D, Altman DG, Barbour V, Macdonald $\mathrm{H}$, Johnston $\mathrm{M}$ et al: Better reporting of interventions: template for intervention description and replication (TIDieR) checklist and guide. BMJ 2014, 348:g1687.

20. Magnusson SP, Hansen M, Langberg H, Miller B, Haraldsson B, Westh EK, Koskinen S, Aagaard P, Kjaer M: The adaptability of tendon to loading differs in men and women. Int J Exp Pathol 2007, 88(4):237-240. 
21. Murphy M, Rio E, Debenham J, Docking S, Travers M, Gibson W: Evaluating the progress of midportion Achilles tendinopathy during rehabilitation: a review of outcome measures for muscle structure and function, tendon structure, and neural and pain associated mechanisms. Int J Sports Phys Ther 2018, 13(3):537-551.

22. administration Tg: Recommended paracetamol doses. In. Canberra; 2013.

23. Silbernagel KG, Thomee R, Eriksson BI, Karlsson J: Full symptomatic recovery does not ensure full recovery of muscle-tendon function in patients with Achilles tendinopathy. Br J Sports Med 2007, 41(4):276-280; discussion 280.

24. Keech AC, Wonders SM, Cook DI, Gebski VJ: Balancing the outcomes: reporting adverse events. Med J Aust 2004, 181(4):215-218.

25. Reilly MC, Zbrozek AS, Dukes EM: The validity and reproducibility of a work productivity and activity impairment instrument. Pharmacoeconomics 1993, 4(5):353-365.

26. Average Weekly Earnings, Australia [https://www.abs.gov.au/statistics/labour/earnings-and-workhours/average-weekly-earnings-australia/latest-release\#key-statistics]

27. Robinson JM, Cook JL, Purdam C, Visentini PJ, Ross J, Maffulli N, Taunton JE, Khan KM: The VISA-A questionnaire: a valid and reliable index of the clinical severity of Achilles tendinopathy. $\mathrm{Br} J$ Sports Med 2001, 35(5):335-341.

28. Munteanu SE, Scott LA, Bonanno DR, Landorf KB, Pizzari T, Cook JL, Menz HB: Effectiveness of customised foot orthoses for Achilles tendinopathy: a randomised controlled trial. Br J Sports Med 2015, 49(15):989-994.

29. Scott W, McCracken LM: Patients' impression of change following treatment for chronic pain: global, specific, a single dimension, or many? J Pain 2015, 16(6):518-526.

30. Maksymowych WP, Richardson R, Mallon C, van der Heijde D, Boonen A: Evaluation and validation of the patient acceptable symptom state (PASS) in patients with ankylosing spondylitis. Arthritis Rheum 2007, 57(1):133-139.

31. Sallis JF, Haskell WL, Wood PD, Fortmann SP, Rogers T, Blair SN, Paffenbarger RS Jr: Physical activity assessment methodology in the five-city project. Am J Epidemiol 1985, 121(1):91-106.

32. Houben RM, Leeuw M, Vlaeyen JW, Goubert L, Picavet HS: Fear of movement/injury in the general population: factor structure and psychometric properties of an adapted version of the tampa scale for kinesiophobia. J Behav Med 2005, 28(5):415-424.

33. Sullivan MJL BS, Pivik J.: The pain catastrophizing scale: development and validation. Psychol Assess 1995, 7:524-532.

34. Freynhagen R, Baron R, Gockel U, Tolle TR: painDETECT: a new screening questionnaire to identify neuropathic components in patients with back pain. Curr Med Res Opin 2006, 22(10):1911-1920.

35. Julious SA: Sample size of 12 per group rule of thumb for a pilot study. Pharmaceut Statist 2005, 4(4):287-291.

36. A new view of statistics [http://sportsci.org/resource/stats ] 
37. Little RJA: A test of missing completely at random for multivariate data with missing values. JASA 1988, 83(404):1198-1202.

38. van Leeuwen MT, Blyth FM, March LM, Nicholas MK, Cousins MJ: Chronic pain and reduced work effectiveness: the hidden cost to Australian employers. Eur J Pain 2006, 10(2):161-166.

39. Beyer R, Kongsgaard M, Hougs Kjaer B, Ohlenschlaeger T, Kjaer M, Magnusson SP: Heavy slow resistance versus eccentric training as treatment for Achilles tendinopathy: a randomized controlled trial. Am J Sports Med 2015, 43(7):1704-1711.

40. Sancho I, Morrissey D, Willy RW, Barton C, Malliaras P: Education and exercise supplemented by a pain-guided hopping intervention for male recreational runners with midportion Achilles tendinopathy: a single cohort feasibility study. Phys Ther Sport 2019, 40:107-116.

41. Silbernagel KG, Thomeé R, Eriksson BI, Karlsson J: Continued sports activity, using a pain-monitoring model, during rehabilitation in patients with Achilles tendinopathy: a randomized controlled study. Am J Sports Med 2007, 35(6):897-906.

42. Higgins J, Thomas J, Chandler J, Cumpston M, Li T, Page MJ, Welch VA: Cochrane handbook for systematic reviews of interventions version 6.0 (updated July 2019). The Cochrane Collaboration 2019.

43. Yelland MJ, Sweeting KR, Lyftogt JA, Ng SK, Scuffham PA, Evans KA: Prolotherapy injections and eccentric loading exercises for painful Achilles tendinosis: a randomised trial. Br J Sports Med 2011, 45(5):421-428.

\section{Tables}

Table 1 Calf exercise dosage for each group. 


\begin{tabular}{|c|c|c|c|c|}
\hline & \multicolumn{2}{|l|}{ High Load } & \multicolumn{2}{|l|}{ Low Load } \\
\hline & $\begin{array}{l}\text { with High TUT } \\
\text { (Group 1) }\end{array}$ & $\begin{array}{l}\text { with Low TUT } \\
\text { (Group 2) }\end{array}$ & $\begin{array}{l}\text { with High TUT } \\
\text { (Group 3) }\end{array}$ & $\begin{array}{l}\text { with Low TUT } \\
\text { (Group 4) }\end{array}$ \\
\hline Load intensity & $6 \mathrm{RM}$ & $6 \mathrm{RM}$ & $18 \mathrm{RM}$ & $18 \mathrm{RM}$ \\
\hline Repetition & 6 & 6 & 18 & 18 \\
\hline Sets & 4 & 4 & 4 & 4 \\
\hline \multirow[t]{2}{*}{ Contraction time/rep } & 3s concentric & 1s concentric & 3s concentric & 1s concentric \\
\hline & 3s eccentric & 1s eccentric & 3s eccentric & 1s eccentric \\
\hline Rest in between reps & No & No & No & No \\
\hline Contraction time per set & $36 \mathrm{~s}$ & $12 \mathrm{~s}$ & $108 \mathrm{~s}$ & $36 \mathrm{~s}$ \\
\hline Total contraction time & $288 \mathrm{~s}$ & $96 \mathrm{~s}$ & $864 \mathrm{~s}$ & $288 \mathrm{~s}$ \\
\hline Volitional muscular failure & Yes & Yes & Yes & Yes \\
\hline \multirow[t]{2}{*}{ Range of motion } & $0^{\circ}$ to $15^{\circ} \mathrm{DF}$ & $0^{\circ}$ to $15^{\circ} \mathrm{DF}$ & $0^{\circ}$ to $15^{\circ} \mathrm{DF}$ & $0^{\circ}$ to $15^{\circ} \mathrm{DF}$ \\
\hline & $0^{\circ}$ to $50^{\circ} \mathrm{PF}$ & $0^{\circ}$ to $50^{\circ} \mathrm{PF}$ & $0^{\circ}$ to $50^{\circ} \mathrm{PF}$ & $0^{\circ}$ to $50^{\circ} \mathrm{PF}$ \\
\hline
\end{tabular}

Abbreviations: TUT, time-under-tension. RM, repetition maximum. TUT, time-under-tension. DF, dorsiflexion; PF, planter flexion. S, seconds

Table 2. Participant characteristics at baseline for each group. Values are mean (SD) unless otherwise noted. 


\begin{tabular}{|c|c|c|c|c|}
\hline & \multicolumn{2}{|l|}{ High Load } & \multicolumn{2}{|l|}{ Low Load } \\
\hline & $\begin{array}{l}\text { with High } \\
\text { TUT }\end{array}$ & $\begin{array}{l}\text { with Low } \\
\text { TUT }\end{array}$ & $\begin{array}{l}\text { with High } \\
\text { TUT }\end{array}$ & $\begin{array}{l}\text { with Low } \\
\text { TUT }\end{array}$ \\
\hline & $(n=12)$ & $(n=12)$ & $(n=12)$ & $(n=12)$ \\
\hline Age, years & $42.0(11.4)$ & $43.0(11.3)$ & $41.6(7.2)$ & $46.3(11.9)$ \\
\hline Height, cm & $177.8(6.2)$ & $176.6(10.3)$ & $178.1(8.2)$ & $175.0(8.2)$ \\
\hline Mass, kg & $89.0(17.9)$ & $97.0(18.1)$ & $84.6(17.1)$ & $94.5(13.7)$ \\
\hline Body mass index, $\mathrm{kg} / \mathrm{m}^{2}$ & $28.0(4.6)$ & $31.1(5.3)$ & $26.6(4.4)$ & $30.6(6.4)$ \\
\hline \multicolumn{5}{|l|}{ Employment* } \\
\hline Full-time & $10(83)$ & $8(67)$ & $10(83)$ & $9(75)$ \\
\hline Part-time & 0 & $1(8)$ & 0 & $1(8)$ \\
\hline Casual & $1(8)$ & $1(8)$ & 0 & $1(8)$ \\
\hline Self-employed & 0 & $2(17)$ & $1(8)$ & $1(8)$ \\
\hline Student & $1(8)$ & 0 & $1(8)$ & 0 \\
\hline Duration of symptoms, monthst & $11.0(39)$ & $54.0(83)$ & $18.0(30)$ & $12.0(36)$ \\
\hline Dominant side, - right* & $11(92)$ & $11(92)$ & $8(67)$ & $10(83)$ \\
\hline $\begin{array}{l}\text { Presentation, unilateral/ bilateral } \\
\text { * }\end{array}$ & $\begin{array}{l}7(58) / 5 \\
(42)\end{array}$ & $\begin{array}{l}6(50) / 6 \\
(50)\end{array}$ & $\begin{array}{l}4(33) / 8 \\
(67)\end{array}$ & $\begin{array}{l}6(50) / 6 \\
(50)\end{array}$ \\
\hline $\begin{array}{l}\text { Achilles tendon AP diameter, } \\
\text { mmq }\end{array}$ & $6.9(1.3)$ & $7.8(1.9)$ & $7.3(2.2)$ & $8.5(3.1)$ \\
\hline Prior exercise treatment, yes * & $3(25)$ & $4(33)$ & $6(50)$ & $8(67)$ \\
\hline Classified Achilles pain quality ^* & $7(58)$ & $10(83)$ & $9(75)$ & $9(75)$ \\
\hline \multicolumn{5}{|l|}{ Intensity of Achilles pain * } \\
\hline Mild & $3(25)$ & $3(25)$ & $2(17)$ & $4(33)$ \\
\hline Moderate & $9(75)$ & $5(42)$ & $8(66)$ & $4(33)$ \\
\hline Severe & 0 & $4(33)$ & $2(17)$ & $4(33)$ \\
\hline VISA-A & $55.3(13.4)$ & $44.8(18.1)$ & $46.0(15.8)$ & $54.7(9.8)$ \\
\hline Pain Detect & $10.0(5.2)$ & $12.2(6.1)$ & $10.0(6.0)$ & $10.0(5.0)$ \\
\hline
\end{tabular}

Table 3. Feasibility outcomes. Values are n (\%) unless otherwise noted. 


\begin{tabular}{|c|c|c|c|c|}
\hline & High Load & & Low Load & \\
\hline & $\begin{array}{l}\text { with High } \\
\text { TUT }\end{array}$ & $\begin{array}{l}\text { with Low } \\
\text { TUT }\end{array}$ & $\begin{array}{l}\text { with High } \\
\text { TUT }\end{array}$ & $\begin{array}{l}\text { with Low } \\
\text { TUT }\end{array}$ \\
\hline Session time duration in minutes* & $43.4(12.2)$ & $39.0(6.1)$ & $53.0(7.3)$ & $37.1(7.0)$ \\
\hline \multicolumn{5}{|l|}{ Adherence $t$} \\
\hline $\begin{array}{l}\text { Number of zoom sessions completed / } \\
12\end{array}$ & $11(92)$ & $9(71)$ & $11(92)$ & $10(79)$ \\
\hline $\begin{array}{l}\text { Number of home sessions completed / } \\
36\end{array}$ & $21(58)$ & $18(49)$ & $21(58)$ & $25(68)$ \\
\hline \multicolumn{5}{|l|}{$\begin{array}{l}\text { Fidelity of exercise dose parameters in } \\
\text { seated }\end{array}$} \\
\hline Time-under-tension & $5(42)$ & $5(42)$ & $6(50)$ & $7(58)$ \\
\hline Volume & $7(58)$ & $8(67)$ & $8(67)$ & $10(83)$ \\
\hline Load intensity & $6(50)$ & $1(8)$ & $8(67)$ & $8(67)$ \\
\hline \multicolumn{5}{|l|}{$\begin{array}{l}\text { Fidelity of exercise dose parameters in } \\
\text { standing }\end{array}$} \\
\hline Time-under-tension & $5(42)$ & $3(25)$ & $6(50)$ & $6(50)$ \\
\hline Volume & $7(58)$ & $7(58)$ & $8(67)$ & $7(58)$ \\
\hline Load intensity & $5(42)$ & $4(33)$ & $9(75)$ & $7(58)$ \\
\hline $\begin{array}{l}\text { No. of participants who reporting } \\
\text { adverse event }\end{array}$ & $8(67)$ & $8(67)$ & $8(67)$ & $6(50)$ \\
\hline \multicolumn{5}{|l|}{ Severity of adverse events 9} \\
\hline Mild & $4(33)$ & $6(50)$ & $8(67)$ & $3(25)$ \\
\hline Moderate & $3(25)$ & $2(17)$ & 0 & $3(25)$ \\
\hline Severe & $1(8)$ & 0 & 0 & 0 \\
\hline Achilles related adverse events & $3(25)$ & $4(33)$ & $4(33)$ & $4(33)$ \\
\hline \multicolumn{5}{|l|}{$\begin{array}{l}\text { Severity of Achilles related adverse } \\
\text { events }\end{array}$} \\
\hline Mild & $3(25)$ & $4(33)$ & $4(33)$ & $3(25)$ \\
\hline Moderate & 0 & 0 & 0 & 0 \\
\hline Severe & 0 & 0 & 0 & 0 \\
\hline $\begin{array}{l}\text { No. of participants who used co- } \\
\text { interventions }\end{array}$ & $3(25)$ & $2(17)$ & $2(17)$ & $4(33)$ \\
\hline
\end{tabular}


No. of participants using paracetamol

Total paracetamol tablets used $\mathbf{9}$
4 (33)

$16(33)$
$5(42)$

$31(33)$
$4(33)$

$33(25)$
$6(50)$

$17(25)$

Abbreviations: TUT, time-under-tension. * Mean (SD); †Median (percentage); Mild: some discomfort noted but without disruption of daily life that goes within 24-28 hrs; Moderate: discomfort enough to affect/reduce normal activity that goes within 3-5days ; Severe: complete inability to perform daily activities and lead a normal life and that requires medical intervention; tablet dose $=500 \mathrm{mg}$;

Table 4. Patient-reported outcomes with effect estimates. Values are mean (SD) unless otherwise noted. 
High Load

with High

TUT with Low

TUT
Low Load

with High TUT

with Low TUT

Self-reported measures

Severity of pain using VISA-A § / 100

\begin{tabular}{lllll} 
Baseline & $55.3(13.4)$ & $44.8(18.1)$ & $46.0(15.8)$ & $54.7(9.8)$ \\
\hline Week-6 & $69.3(14.8)$ & $65.2(16.7)$ & $63.2(16.8)$ & $68.5(14.0)$ \\
\hline Week-12 & $81.5(11.2)$ & $80.7(17.5)$ & $86.3(9.0)$ & $83.8(13.0)$ \\
\hline $\begin{array}{l}\text { Mean Difference at 6- } \\
\text { weeks, [95\%Cl] }\end{array}$ & $14.0[2,26]$ & $20.4[6,35]$ & $17.2[4,30]$ & $13.8[4,23]$ \\
\hline $\begin{array}{l}\text { Mean Difference at 12- } \\
\text { weeks, [95\%Cl] }\end{array}$ & 26.2 & $35.9[21,51]$ & $40.3[30,51]$ & $29.1[20,38]$ \\
\hline SMD baseline-week 6 & 0.9 & 1.0 & 0.9 & 1.0 \\
\hline SMD baseline-week 12 & 1.5 & 1.4 & 1.7 & 1.6
\end{tabular}

Worst pain using Numerical Pain Rating Scale / 10**

\begin{tabular}{lllll} 
Baseline & $5.0(2.2)$ & $4.8(3.2)$ & $4.7(3.0)$ & $5.0(3.0)$ \\
\hline Week-6 & $2.4(2.5)$ & $2.2(1.0)$ & $3.1(2.2)$ & $3.3(2.2)$ \\
\hline Week-12 & $3.4(2.7)$ & $2.3(2.0)$ & $2.1(2.3)$ & $2.3(1.8)$ \\
\hline $\begin{array}{l}\text { Mean Difference at 6- } \\
\text { weeks, [95\%Cl] }\end{array}$ & $-2.6[-5 .-1]$ & $-2.6[-5 .-1]$ & $-1.6[-4,1]$ & $-1.7[-4,0.4]$ \\
\hline $\begin{array}{l}\text { Mean Difference at 12- } \\
\text { weeks, [95\%Cl] }\end{array}$ & $-1.6[-4,1]$ & $-2.5[-5,-0.3]$ & $-2.6[-5,-0.5]$ & $-2.7[-5,-1]$ \\
\hline SMD baseline-week 6 & -1.0 & -1.0 & -0.6 & -0.7 \\
\hline SMD baseline-week 12 & -0.6 & -0.9 & -0.9 & -1.0
\end{tabular}

EQ-5D-5L, Index †+/ 1

\begin{tabular}{|c|c|c|c|c|}
\hline Baseline & $0.71(0.10)$ & $0.71(0.17)$ & $0.72(0.10)$ & $0.74(0.10)$ \\
\hline Week-6 & $0.79(0.09)$ & $0.76(0.16)$ & $0.76(0.10)$ & $0.78(0.14)$ \\
\hline Week-12 & $0.84(0.11)$ & $0.88(0.14)$ & $0.84(0.11)$ & $0.87(0.12)$ \\
\hline $\begin{array}{l}\text { Mean Difference at 6- } \\
\text { weeks, [95\%Cl] }\end{array}$ & $\begin{array}{l}0.08 \\
{[0,0.16]}\end{array}$ & $\begin{array}{l}0.05 \\
{[-0.16,0]}\end{array}$ & $0.04[-0.12,0]$ & $0.03[-0.13,0]$ \\
\hline $\begin{array}{l}\text { Mean Difference at 12- } \\
\text { weeks, }[95 \% \mathrm{Cl}]\end{array}$ & $\begin{array}{l}0.13 \\
{[0.04,0.22]}\end{array}$ & $\begin{array}{l}0.17 \\
{[0.09,0.25]}\end{array}$ & $0.12[0.04,0.20]$ & $0.13[0.05,0.21]$ \\
\hline SMD baseline-week 6 & 0.9 & 0.3 & 0.4 & 0.3 \\
\hline
\end{tabular}


SMD baseline-week 12

EQ-5D-5L, VAS 执 / 100

Baseline

Week-6

Week-12

Mean Difference at 6weeks, [95\% Cl]

Mean Difference at 12weeks, [95\% Cl]

SMD baseline-week 6

SMD baseline-week 12

7-Day Activity Recall §§

\section{Baseline}

Week-6

Week-12

Mean Difference at 6-

weeks, [95\% Cl]

Mean Difference at 12-

weeks, [95\% Cl]

SMD baseline-week 6

SMD baseline-week 12
1.2

$67.8(15.2)$

$82.2(8.5)$

83.4 (13.2)

$14.4[4,24]$

$15.6[4,28]$

1.0

1.0 1041 (170) $1322(257)$

$1071(241)$

$837(555)$

29

$[-149,207] \quad[-216,197]$

$-204$

$[-579,171]$

$-7$

$[-203,189]$

0.1

$-0.5$

0

0

0.2
1.0

$69.6(12.0)$

75.7 (13.6)

$74.0(11.5)$

$6.1[-4,17]$

$4.4[-5,14]$

$9.5[-2,21]$

0.6

0.5

0.7

0.7

0.4

Tampa Scale for Kinesiophobia 9/ 68

\begin{tabular}{lllll} 
Baseline & $39.8(8.7)$ & $39.7(3.6)$ & $37.2(4.9)$ & $35.1(12.5)$ \\
\hline Week-6 & $34.5(8.3)$ & $35.0(6.1)$ & $34.9(4.1)$ & $30.8(6.8)$ \\
\hline Week-12 & $30.2(6.4)$ & $29.3(6.1)$ & $32.3(6.4)$ & $27.2(4.5)$ \\
\hline $\begin{array}{l}\text { Mean Difference at 6- } \\
\text { weeks, [95\%Cl] }\end{array}$ & $-5.3[-13,2]$ & $-4.7[-9,-0.4]$ & $-2.3[-6,1]$ & $-4.3[-12,4]$ \\
\hline $\begin{array}{l}\text { Mean Difference at 12- } \\
\text { weeks, [95\%Cl] }\end{array}$ & $-9.6[-16,-4]$ & $-10.4[-15,-6]$ & $-4.9[-9,-0.3]$ & $-7.9[-15,-0.3]$ \\
\hline SMD baseline-week 6 & -0.6 & -0.9 & -0.5 & -0.4 \\
\hline SMD baseline-week 12 & -1.1 & -1.5 & -0.8 & -0.8
\end{tabular}

Pain Catastrophising Scale 99/ 52 


\begin{tabular}{|c|c|c|c|c|}
\hline Baseline & $12.8(6.4)$ & $17.3(16.5)$ & $9.4(7.7)$ & $11.4(11.3)$ \\
\hline Week-6 & $6.9(3.2)$ & $8.0(7.0)$ & $7.3(5.9)$ & $6.1(5.4)$ \\
\hline Week-12 & $4.3(4.2)$ & $5.6(6.2)$ & $5.3(5.9)$ & $2.7(2.1)$ \\
\hline $\begin{array}{l}\text { Mean Difference at 6- } \\
\text { weeks, [95\%Cl] }\end{array}$ & $-6.1[-10,-2]$ & $-9.3[-20,1]$ & $-2.1[-8,3]$ & $-5.3[-12,2]$ \\
\hline $\begin{array}{l}\text { Mean Difference at 12- } \\
\text { weeks, [95\%Cl] }\end{array}$ & $-8.5[-13,-4]$ & $-11.7[-22,-2]$ & $-4.1[-10,2]$ & $-8.7[-15,-2]$ \\
\hline SMD baseline-week 6 & -1.0 & -0.7 & -0.3 & -0.6 \\
\hline SMD baseline-week 12 & -1.2 & -0.9 & -0.6 & -1.0 \\
\hline \multicolumn{5}{|c|}{ Patient Impression of Change for pain ${ }^{\wedge} *$} \\
\hline Week-6 (improve) & $8(67)$ & $9(82)$ & $5(42)$ & $8(67)$ \\
\hline Week-12 (improve) & $7(78)$ & $10(100)$ & $10(91)$ & $9(82)$ \\
\hline \multicolumn{5}{|c|}{ Patient Impression of Change for function ${ }^{\wedge}$} \\
\hline Week-6 (improve) & $7(58)$ & $8(73)$ & $4(33)$ & $9(75)$ \\
\hline Week-12 (improve) & $7(78)$ & $10(100)$ & $10(91)$ & $9(100)$ \\
\hline \multicolumn{5}{|c|}{ Patient-Acceptable Symptom State instrument for satisfaction * } \\
\hline Week-6 (50\% improve) & $5(42)$ & $1(10)$ & $4(33)$ & $5(42)$ \\
\hline Week-6 (100\% improve) & $7(58)$ & $9(90)$ & $8(67)$ & $7(58)$ \\
\hline Week-12 (50\% improve) & $2(22)$ & 0 & $2(18)$ & $2(17)$ \\
\hline Week-12 (100\% improve) & $7(78)$ & $10(100)$ & $9(82)$ & $10(83)$ \\
\hline
\end{tabular}

Abbreviations: §Scores on the VISA-A range from 0 (worst Achilles symptoms) to 100 (no Achilles tendinopathy). ** worst pain during the week scored on the NPRS range from 0 (no pain) to 10 (worst pain imaginable). $++S c o r e s$ on the EQ-5D-5L Index Value range from $<0$ (worse than dead) to 0 (dead) to 1 (full health). $\neq \neq S$ cores on the EQ-5D-5L VAS range from 0 (worst imaginable health state) to 100 (best imaginable health state). $\S \S S c o r e s$ on the PAR are represented as daily energy expenditure (kilocalories per day). Tampa score ranges from 17 (no fear of movement) to 68 (greater fear of movement). Scores on CPS range from 0 (no pain) to 52 (higher levels of pain catastrophising). ${ }^{\wedge}$ dichotomised scores to "improved" and "not improved". *n (\%).

Table 5. Performance outcomes with effect size estimates and mean difference (mean \pm SD) 


\begin{tabular}{|c|c|c|c|c|}
\hline & \multicolumn{2}{|l|}{ High Load } & \multicolumn{2}{|l|}{ Low Load } \\
\hline & with High TUT & with Low TUT & with High TUT & with Low TUT \\
\hline \multicolumn{5}{|c|}{ Ankle plantarflexion torque (Nm) } \\
\hline Baseline & $188.4(43.1)$ & $194.9(60.8)$ & $188.6(53.8)$ & $188.5(66.2)$ \\
\hline Week-12 & $225.8(32.9)$ & $220.0(42.8)$ & $204.9(58.0)$ & $206.8(40.0)$ \\
\hline Mean Difference, [95 \% Cl] & $37.4[4,71]$ & $25.1[-18,69]$ & $16.3[-28,62]$ & $18.3[-26,63]$ \\
\hline SMD baseline-week 12 & 0.9 & 0.5 & 0.3 & 0.3 \\
\hline \multicolumn{5}{|c|}{ Ankle plantarflexion rated of torque development (Nm/s) } \\
\hline Baseline & $644.5(235.3)$ & $637.4(326.6)$ & $635.9(215.8)$ & $557.1(197.5)$ \\
\hline Week-12 & $850.4(174.4)$ & $738.9(189.0)$ & $699.9(183.4)$ & $668.6(170.4)$ \\
\hline Mean Difference, [95 \% Cl] & $205.5[26,385]$ & $101.5[-117,320]$ & $64.0[-96,224]$ & $111.5[-39,261]$ \\
\hline SMD baseline-week 12 & 0.9 & 0.4 & 0.3 & 0.6 \\
\hline \multicolumn{5}{|c|}{ Plantarflexor coefficient of variation of torque } \\
\hline Baseline & $1.9(0.8)$ & $1.9(0.4)$ & $2.3(1.0)$ & $2.2(1.0)$ \\
\hline Week-12 & $1.6(0.2)$ & $1.6(0.9)$ & $1.9(1.0)$ & $1.7(1.0)$ \\
\hline Mean Difference, [95 \% Cl] & $-0.3[-0.8,0.2]$ & $-0.3[-0.9,0.3]$ & $-0.4[-1,0.3]$ & $-0.5[-1,0.3]$ \\
\hline SMD baseline-week 12 & -0.4 & -0.4 & -0.4 & -0.5 \\
\hline \multicolumn{5}{|l|}{ Mass lifted in seated (kg) } \\
\hline Baseline & $54.5(20.2)$ & $38.3(23.4)$ & $45.8(10.2)$ & $56.3(17.2)$ \\
\hline Week-12 & $77.5(41.8)$ & $64.0(19.1)$ & $70.8(25.0)$ & $79.4(26.0)$ \\
\hline Mean Difference, [95 \% Cl] & $23.0[-8,54]$ & $25.7[8,44]$ & $24.0[9,40]$ & $23.1[5,42]$ \\
\hline SMD baseline-week 12 & 0.7 & 1.0 & 1.2 & 1.0 \\
\hline \multicolumn{5}{|l|}{ Mass lifted in standing (kg) } \\
\hline Baseline & $13.1(8.7)$ & $11.2(14.0)$ & $9.5(7.1)$ & $8.3(9.5)$ \\
\hline Week-12 & $27.4(14.1)$ & $18.0(12.0)$ & $16.2(11.4)$ & $22.1(23.3)$ \\
\hline Mean Difference, [95 \% Cl] & $14.3[3,26]$ & $6.8[-4,18]$ & $6.7[-1,14]$ & $13.8[-1,29]$ \\
\hline SMD baseline-week 12 & 1.1 & 0.5 & 0.7 & 0.8 \\
\hline
\end{tabular}

\section{Figures}




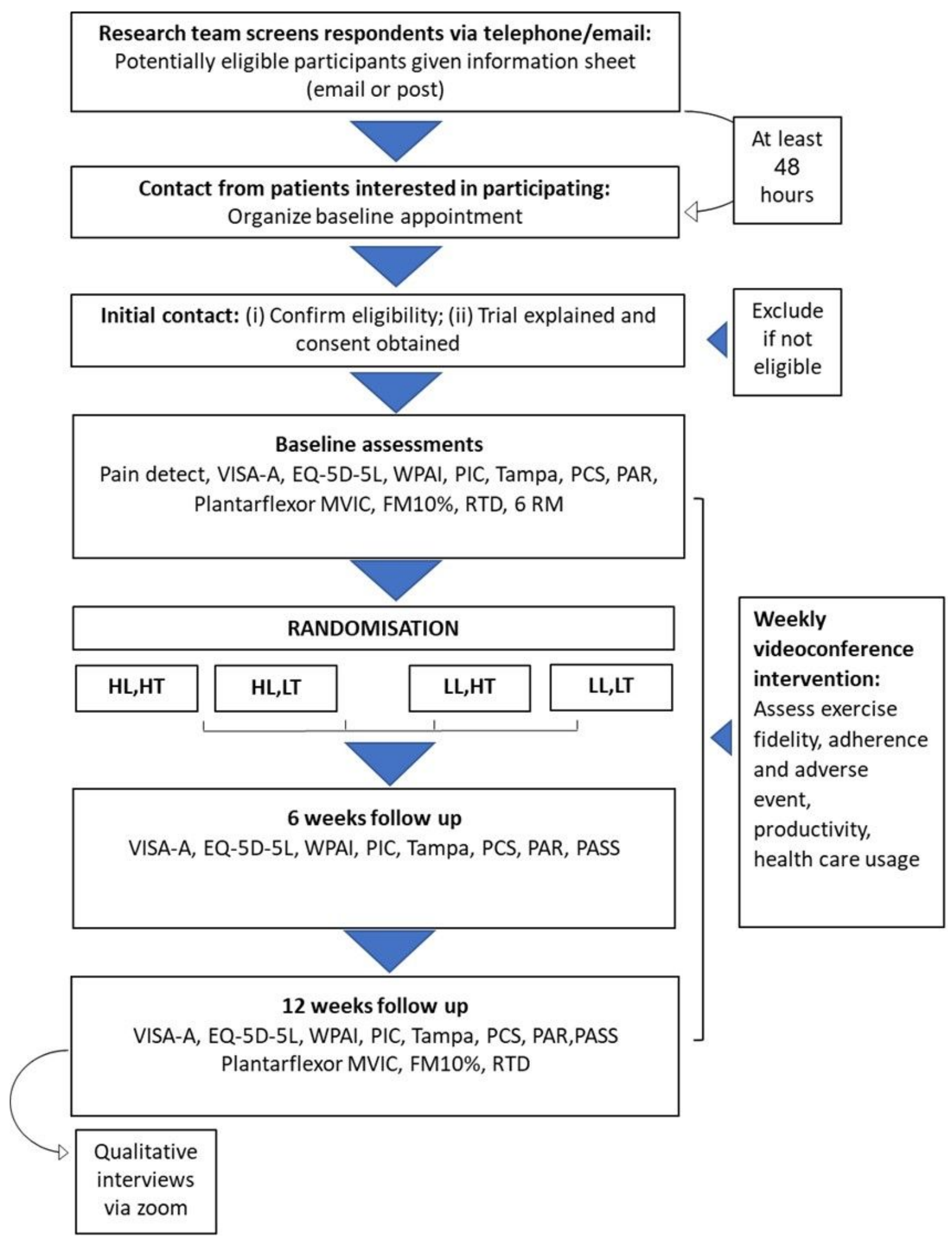

Figure 1

Trial profile. 


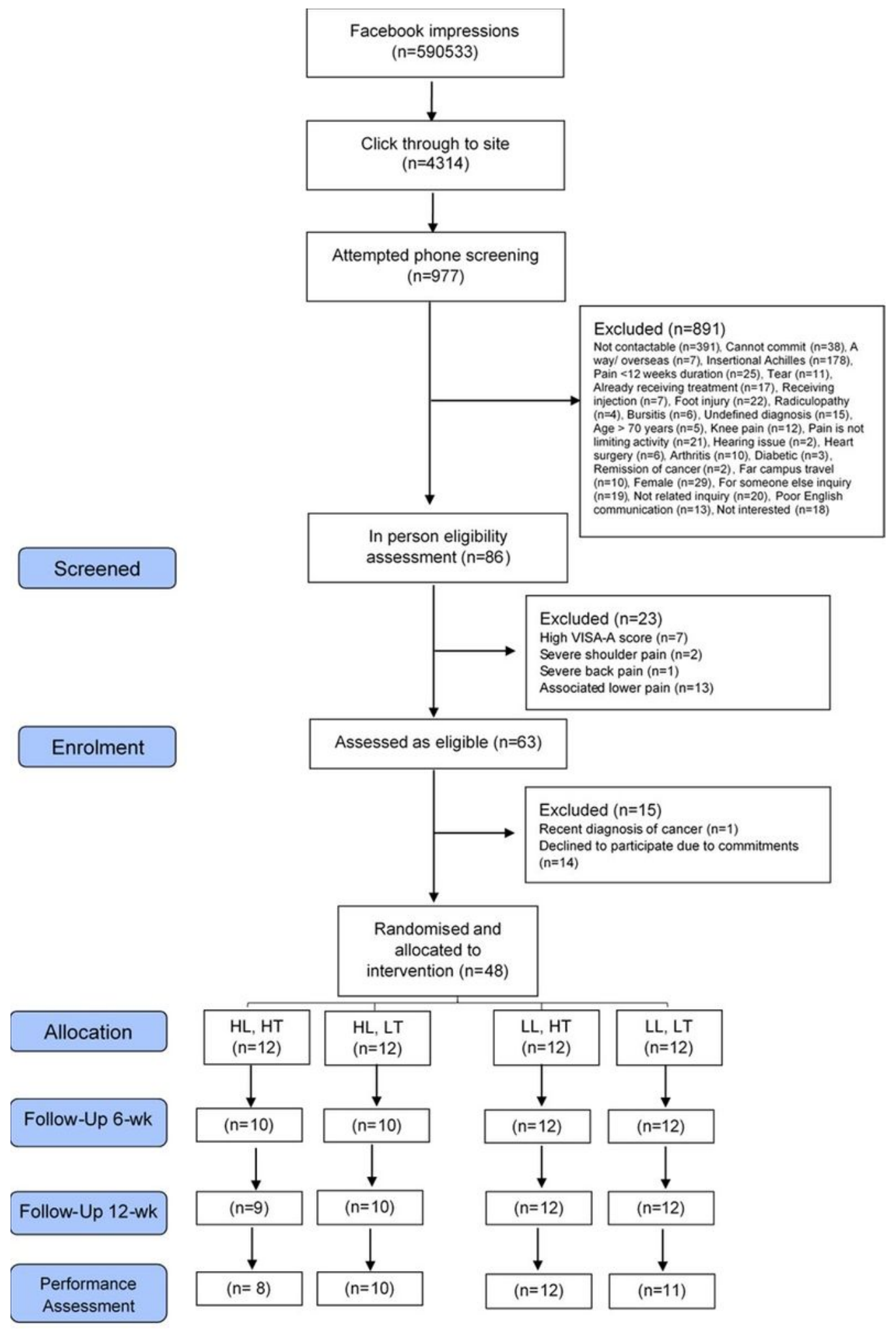

\section{Figure 2}

The CONSORT flow diagram of participants through the study. 


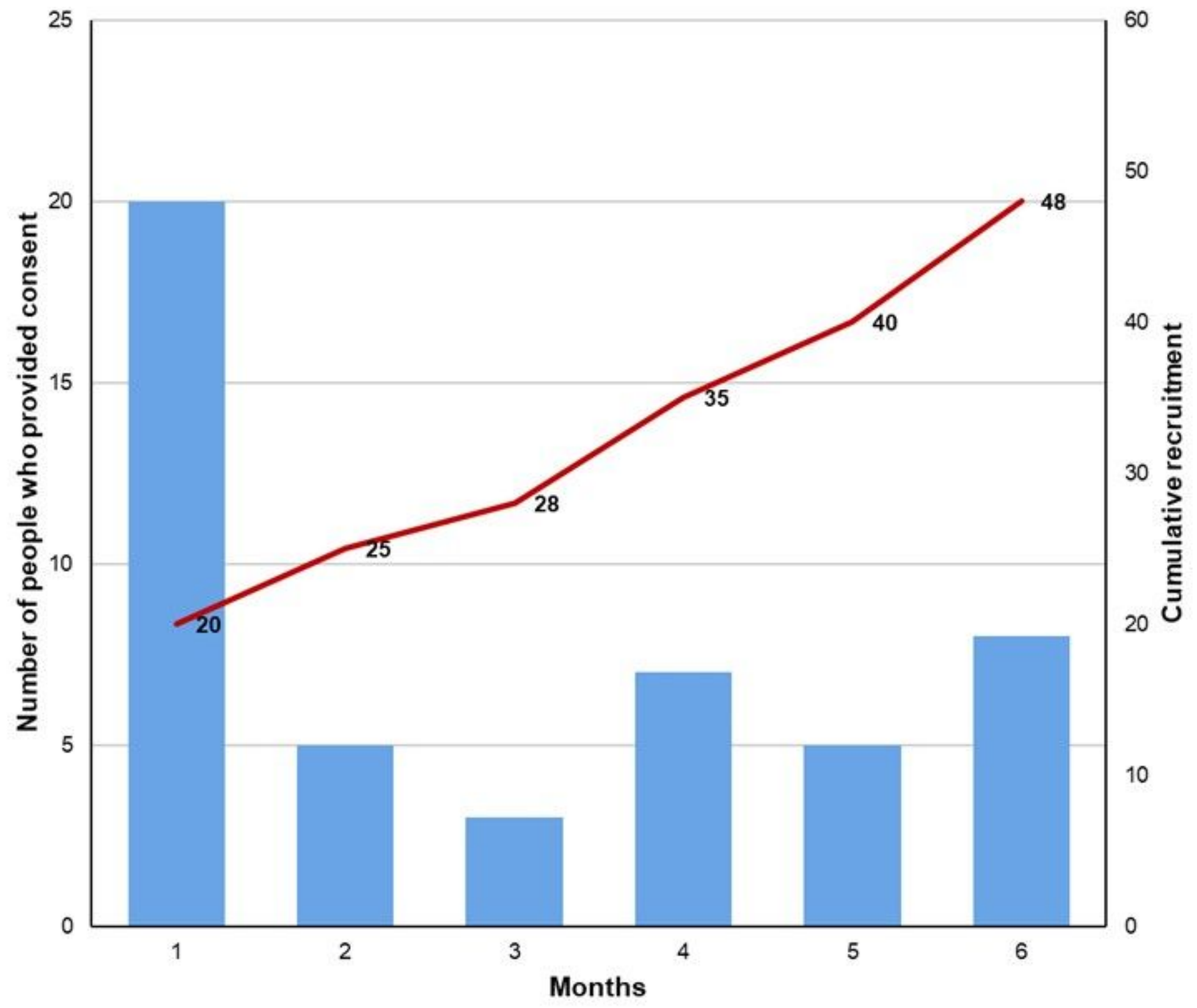

Figure 3

Monthly and cumulative recruitment to the feasibility trial. 
Fidelity in seated calf raises

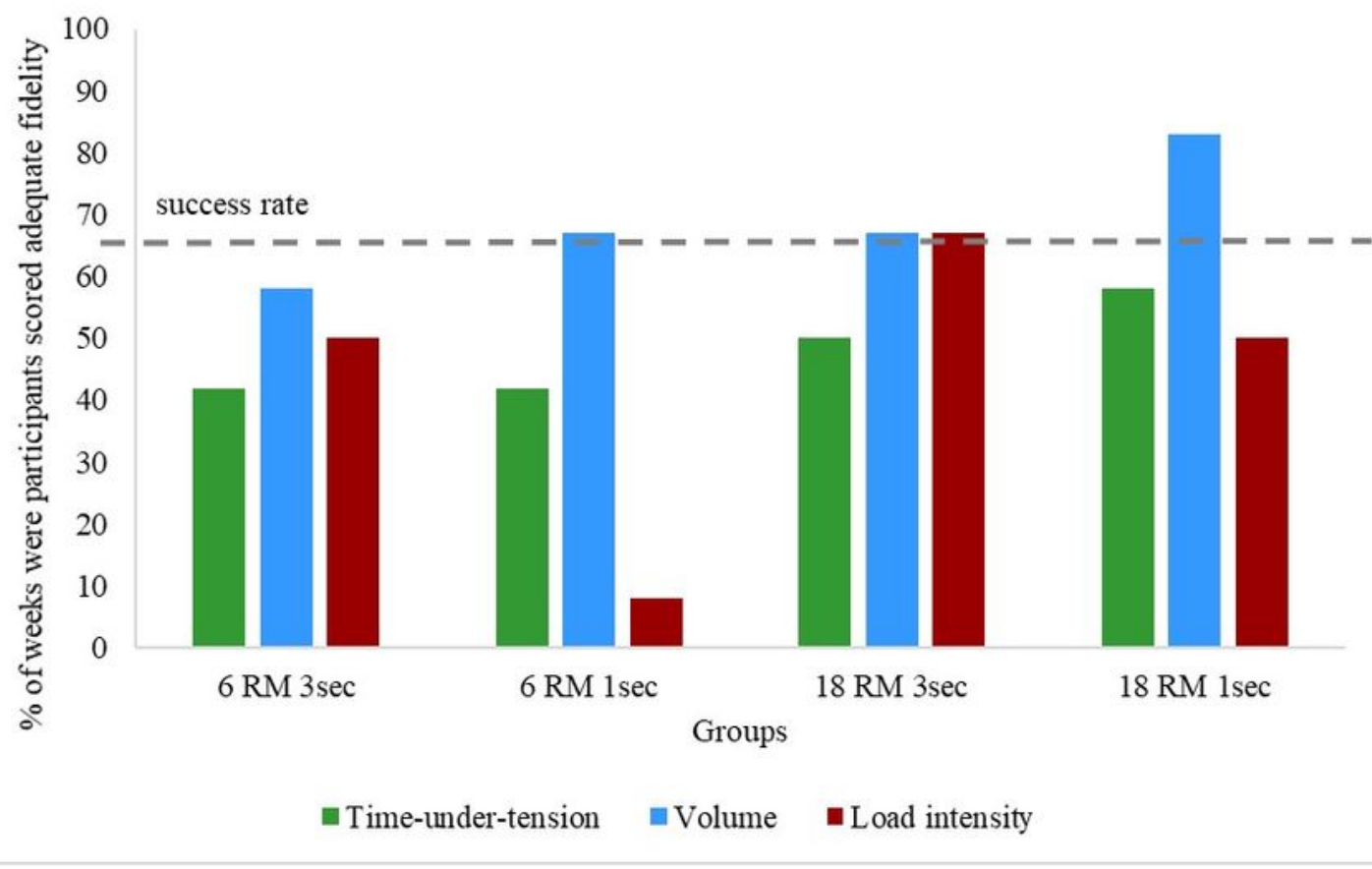

Fidelity in standing calf raises

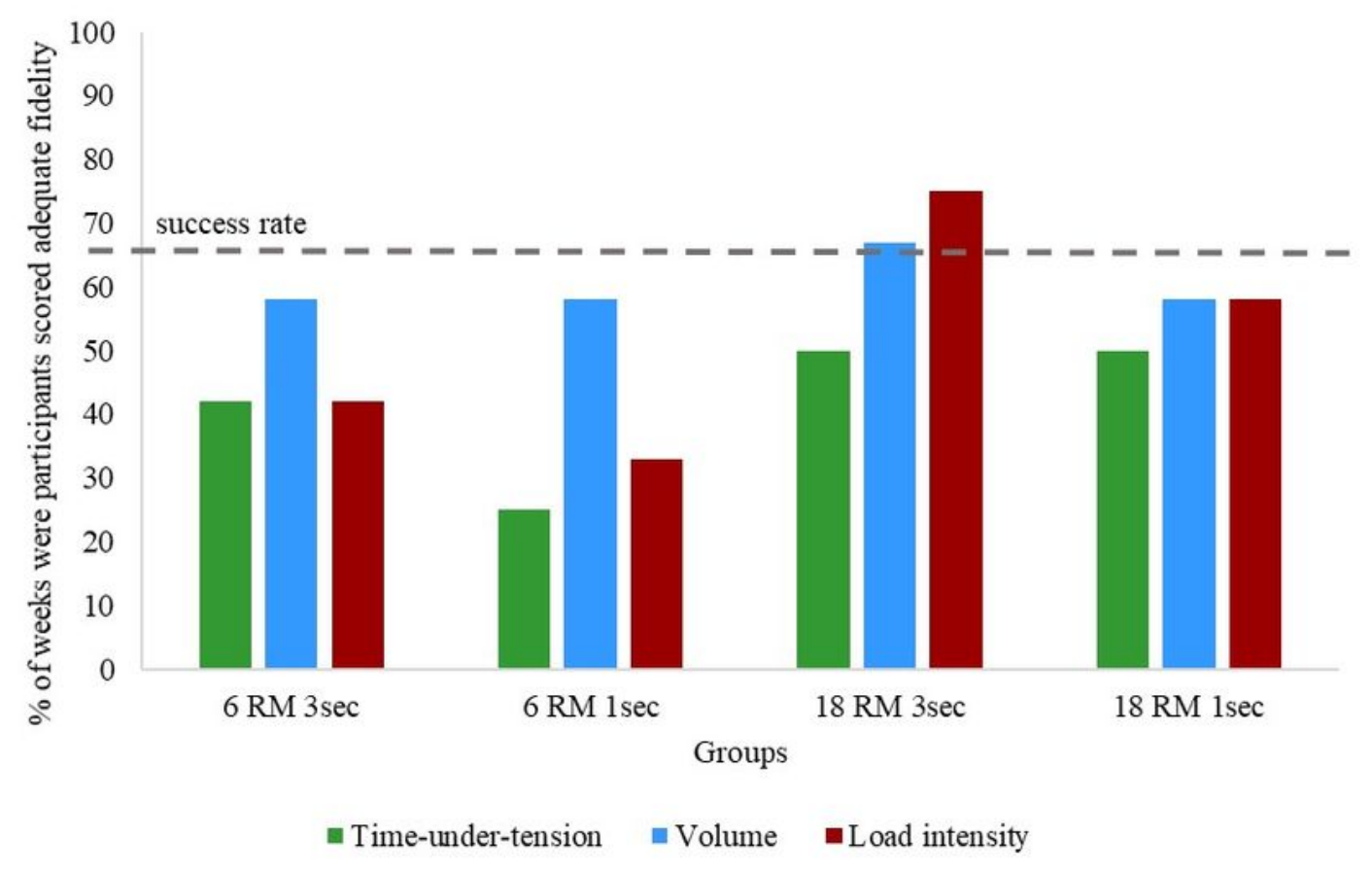

Figure 4

Exercise fidelity of the individual exercise dose parameters for each participant per group. 


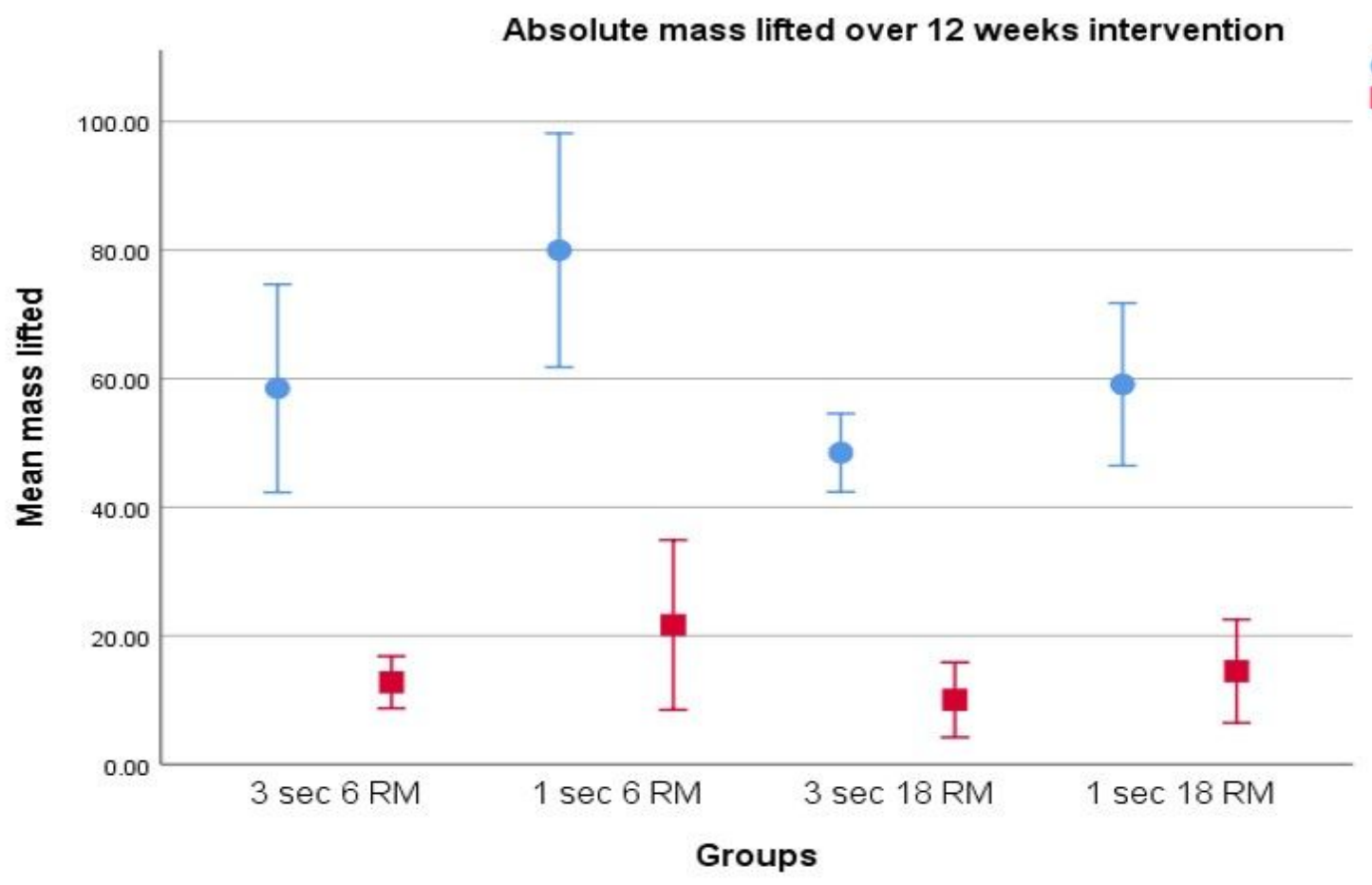

Error Bars: $95 \% \mathrm{Cl}$

\section{Figure 5}

Overall absolute mass lifted during the intervention.

\section{Supplementary Files}

This is a list of supplementary files associated with this preprint. Click to download.

- Additionalfile1.docx

- Additionalfile2.docx

- CONSORTextension.doc 